the Symposium, the editor's task was clearly not an easy one. It has been well and carefully done.

Since the formation of the Bone and Tooth Society in 1950 , a variety of research tools has provided a wealth of data for analysis and digestion. Microradiography, electron microscopy, histochemistry, bone biopsy, tetracycline labelling, radio-isotope tracer studies, not to mention spectacular advances in biochemistry have revolutionized thinking about the dynamic behaviour of bone. For the treatment of patients with bone diseases, a much better model of bone behaviour is now available. These techniques and some of the advances they have produced are well represented in this Symposium, at which the balance between experimental and purely laboratory work on one hand, and clinical and closely allied investigations on the other, seems to have been a reasonable one.

There is a group of four papers related to the use of tetracycline as a marker. There are two papers devoted primarily to studies of bone turnover using microradiographic techniques. There are two papers on the role of the adrenals in the control of calcium-levels in plasma, one paper on hypercalcaemia associated with carcinoma of the breast and a prescient article on calcitonin, based on a consideration of Copp's work, of control systems in general, and of experimental evidence relating magnesium and parathormone.

The interest in kinetic studies is reflected in the considerable number of papers in which calcium or strontium isotopes were the fundamontal tools. The hazards of nuclear fission and fusion and terrestrial contamination have brought as a useful by-product a great deal of fundamental work on bone-seeking isotopes with studies on their location in bones and teeth.

A vastly increased interest in bone matrix and its components is manifest in this Symposium, and no fewer than nine papers can be said to be related to this topic. By contrast, fewer than half this number of papers is concernod with inorganic and physical chemical investigations of bone mineral and related compounds.

Two clinical papers are devoted specifically to studies in human osteoporosis. There is a very detailed and precisely documented account of 42 cases of idiopathic osteoporosis in men younger than fifty-five years, with comments on treatment by oestrogens and calcium supplements. The other paper is concerned with the effect of calcium supplements on the spinal density of patients with osteoporosis, the spinal density being estimated by a densitometric analysis of lateral tomograms of the lumbar spine and intervertebral disks.

There are single papers on many other topics-organ culture, enzymes of cells in bone, the structure of dental enamel, the tensile strength of human compact bone, parallel chemical and microradiographic studies of osteoporotic, osteomalacic and normal human bone, a palaeont. ologist's account of the origin of bone, etc.

This Symposium offers a useful selection of the contributions of European workers to the advancement of knowledge of living bone up to April 1963.

$$
\text { F. H. DOyle }
$$

\section{A PROBLEM OF AGE}

\section{Ageing}

The Biology of Senescence. By Dr. Alex Comfort. Revised and re-set edition. Pp. xvi 365 . (London: Routledge and Kegan Paul, Ltd., 1964.) 42s. net.

$$
\mathrm{T}
$$

EN to fifteen years ago, Dr. Korenchevsky, who may be regarded as the father of gerontology as an organized, internationally recognized research discipline, often recalled the fact that his early years in ageing research had not been easy. Often he came up against official criticism of his plans for studying the processes of ageing. The young research worker intending to embark on a career aimed at the study of the diseases of the elderly, or the processes which bring about changes in ageing organisms, will not to-day be met by such lack of interest. Gerontology has become a scientifically and socially acceptable subject. In Britain the universal interest in the 'ageing problem' has been exemplified by the numerous popular articles and radio and television programmes which, over the past few years, have brought the layman into contact with the research worker. One of the foremost exponents of this popularization of gerontology has been Dr. Alex Comfort, but proof, if such is needed, that the scientific knowledge on which the popular story is based has also been developing apace can be obtained from the fact that Dr. Comfort's earlier book The Biology of Senescence has had to be republished in a completely revised form within oight years.

It is not fair to judge new editions of books solely on the basis of statistics, but in a relatively new field it is comforting for practitioners to be able to point to the advancement of their subject by a more than 40 per cent increase in the size of the new edition.

During the past ten or eleven years Dr. Comfort has been in the forefront of one particular aspect of ageing research, namely, the application of analytical procedures to the study of a variety of parameters which alter with age. His work has, in the main, been concerned with non-human populations, and it is not surprising that the bulk of the material presented represents an assessment of his own findings in the light of the observations of other workers throughout the world. Although this preoccupation with survival tables is understandable, it might give a rather lop-sided view of the progress of gerontology over the past decade to any newcomer to the field who treated the sub-title of the book in its broadest sense and looked for a fuller coverage of the work of those groups which have been considering biological changes in ageing in the present-day fashion at a molecular level.

Although this type of approach is mentioned in passing, the references are more in the nature of an annotated bibliography than a true review of the situation, and it is significant that such references appear, in the main, in the introductory chapters.

One interesting inclusion in the new edition is a chapter on the effect of ionizing radiations. Here the reader is introduced to the beginnings of what will obviously provide a basis for much future work, but its inclusion does demonstrate one of the marked changes which have occurred in the approach to ageing since the first edition was published.

To many readers the section of the book which immediately attracts attention is the chapter on the mechanism of senescence, if only because the theoretical background to a subject always excites most interest. It is therefore a little discouraging that only one new sub-section has been introduced in the new edition. This apparent dearth of new ideas is not, however, so pronounced as would appear from the retention of the old headings. New material on the concepts of somatic mutation, cellular turnover and death, and hormonal control of ageing are discussed at some length, but again the possibilities of the prime lesion being at a molecular level are dismissed in a page.

Ageing can be studied at a variety of levels, dealing respectively with populations, the intact organism, the hormones, the cell, the gene, the enzyme and the molecule. Dr. Comfort's book deals in the main with the first half of this list, but although workers in other fields may regret the lack of coverage of the latter half, the excellence of the author's presentation does much to justify his more limited approach and should act as a stimulus to other writers to provide a review of the relevant material.

Gerontology, or geratology as Dr. Comfort would like to see it called, has come of age. No longer can one author do it justice. 